\title{
Chronic Subdural Hematoma in the Aged
}

\author{
Shiro WagA, Kinya Ohtsubo, Masatsune Ishikawa and Hajime Handa
}

There have been a few reports concerning chiefly the elderly patients with chronic subdural hematoma ${ }^{51,11,, 13), 15)}$.

A total of 106 patients of chronic subdural hematoma, excluding the patients under the age of 10, was experienced during 10 years from 1963 through 1972. Out of 106 patients 24 ( 22.6 per cent) were older than 60 years old. Here we are presenting the clinical analysis on 24 elderly patients with chronic subdural hematoma.

There were 21 male patients and 3 female ones. The ratio of male to female was 7:1 in the aged, whereas in the total of 106 patients the ratio was $14: 1$. Only 4 male patients were over 70 years old (Fig. 1).

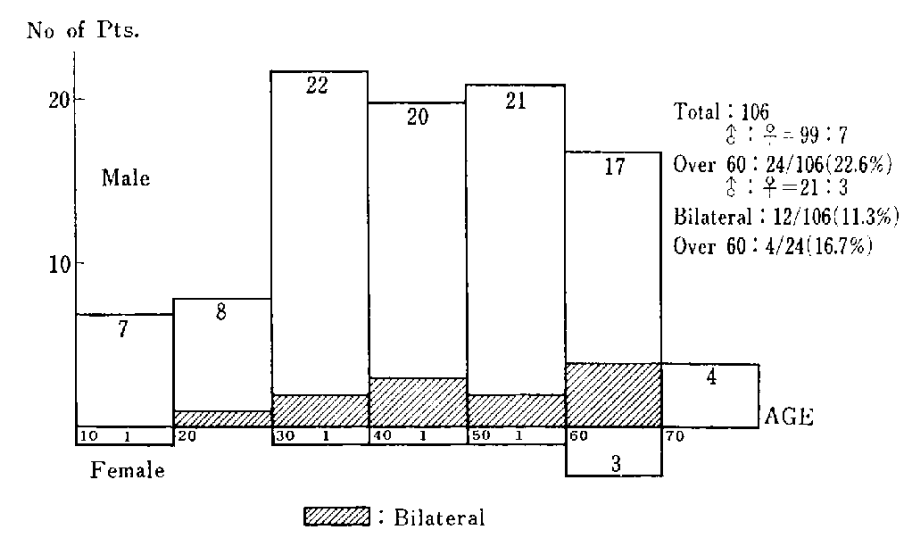

Fig. 1 Age and Distribution of Patients of Chronic Sabdural Hematoma (1963-1972)

Table 1 History of Head Injury in Patients of Chronic

Subdural Hematoma in the Aged (1963 1972)

\begin{tabular}{clr}
\hline Yes & \multicolumn{1}{c}{23} & \\
& traffic accident & 12 \\
& fall down & 10 \\
struck against a door & 1 \\
No & \multicolumn{1}{c}{1} &
\end{tabular}

The history of head injury was summarized in Table 1. Twenty-three out of 24 (96 per cent) had a history of head injury. Closer interrogation had been done even

Department of Neurosurgery, Kyoto University Medical School, Kyoto, JAPAN. 
Table 2 Initial Symptoms in Patients of Chronic Subdural Hematoma in the Aged (1963 1972)

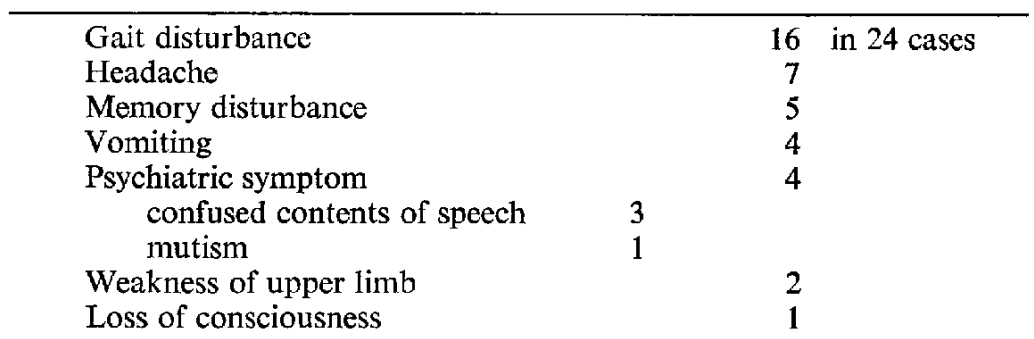

Table 3 First Admission to Other Departments in Patients of Chronic Subdural Hematoma in the Aged (1963 1972)

\begin{tabular}{cc}
\hline To the Medical Ward & 11 \\
To the Geviatric Ward & 1 \\
First Diagnosis in Other Departments & 6 \\
Cerebral Vascular Lesion & 1 ) \\
(vertebrobasilar thrombosis & 1 \\
Diabetes mellitus & 4 \\
Unknown & 1
\end{tabular}

after the surgical evacuation of the hematoma. In 13 patients the head injury was very slight and not followed by loss of consciousness. In another 9 the head injury was moderate in severity and accompanied by a short period of loss of consciousness up to a few hours. In a woman of 64 years old, epidural hematoma had been evacuated immediately after the injury, 7 months perior to the surgical evacuation of the contralateral chronic subdural hematoma.

Initial symptoms of chronic subdural hematoma in the aged were somewhat characteristic (Table 2). They were of gait disturbance (67 per cent), psychiatric manifestations ( 38 per cent) including memory disturbance ( 21 per cent) and confused contents of speech and mutism (17 per cent), headache ( 29 per cent), and vomiting (17 per cent).

Although the history of a probable causative injury was obtained from 23 patients including closer interrogation after the surgical treatment, 12 patients (50 per cent) had been admitted to medical and geriatric departments because of neurological and/or neuropsychiatric symptoms. The diagnoses were cerebrovascular lesion and others (Table 3).

Neurological signs and symptoms on admission to the Neurosurgical Department were shown in Table 4. Hemiparesis was a sign in 75 per cent of the patients. Headache was only a symptom in 38 per cent of the total and was a symptom in 50 per cent of the fully conscious patients. Characteristic sign was urinary incontinence, which was present in 8 fully conscious patients ( 33 per cent of the total and 50 per cent of the fully conscious patients). Psychiatric symptoms including memory dis- 
Table 4 Neurological Signs and Symptoms on Admission in Patients of Chronic Subdural Hematoma in the Aged (1963 1972)

$\begin{array}{lc}\text { Hemiparesis } & 18 \\ \text { Headache (fully conscious patient) } & 9 \\ \text { Incontinence (fully conscious patient) } & 8 \\ \text { Disturbed conscious level } & 8 \\ \text { Memory disturbance } & 7 \\ \text { Disorientation } & 6 \\ \text { Motor aphasia } & 6 \\ \text { Choked disc } & 6 \\ \text { Mutism and/or initiativelessness } & 5 \\ \text { Anisocoria } & 4 \\ \text { Ataxia } & 3 \\ \text { Vomiting } & 2 \\ \text { Convulsion } & 1 \\ \text { Remission } & 8 \\ & \end{array}$

Table 5 Diagnosis on Admission to the Neurosurgical Department at Kyoto University Medical School in Patients of Chronic Subdural Hematoma in the Aged (1963 1972)

\begin{tabular}{ll}
\hline $\begin{array}{c}\text { Chronic Subdural Hematoma } \\
\quad \text { (including those already diagnosed }\end{array}$ & 15 \\
$\quad$ by angiography) & \\
Brain tumor & 7 \\
Cerebral Vascular Lesion & 2
\end{tabular}

turbance, disorientation, mutism and initiativelessness were found in one-sixth to one-fourth of patients. Choked disc was present in only 25 per cent of patients. There were vomiting in two and convulsion in one. Ataxia ${ }^{14}$ was present in three. Characteristically, remission of symptoms in the course prior to admission was present in onethird.

The average interval from the time of head injury to the surgical treatment was 87.8 days in 23 patients. And the average interval between the initial symptoms and the surgery was 34.4 days in 24 patients.

Interestingly, the diagnosis on admission to the Neurosurgical Department was shown in Table 5. Including the patients who had been already diagnosed by carotid angiography in the Outpatient Clinic, only 15 (63 per cent) were correctly diagnosed. By only neurological examination, 7 ( 29 per cent) were diagnosed as brain tumors and 2 (8 per cent) were of cerebrovascular lesions.

All the patients were diagnosed by carotid angiography and 4 out of 24 (17 per cent) had bilateral lesions (Fig. 1). A total of 28 lesions had all surgical evacuation. Operative technique and time required were summarized in Table 6.

Results of surgical treatment were satisfactory (Table 7). There was neither surgical death nor postoperative deterioration. In only one patient, 71-year-old male, 
Table 6 Operative Technique and Time Required in Patients of Chronic Subdural Hematoma in the Aged (1963 1972)

\begin{tabular}{|c|c|c|c|c|}
\hline \multicolumn{3}{|c|}{ Classical craniotomy } & & $76.7 \mathrm{~min}$. \\
\hline \multicolumn{3}{|c|}{ Craniotomy with Circular Saw } & 5 & $96.0 \mathrm{~min}$. \\
\hline Burr hole & & & 20 & $78.7 \mathrm{~min}$. \\
\hline one & 4 & $30.0 \mathrm{~min}$. & & \\
\hline two & 10 & $79.5 \mathrm{~min}$. & & \\
\hline three & 6 & $110.0 \mathrm{~min}$. & & \\
\hline
\end{tabular}

Table 7 Results of Treatment in Patients of Chronic Subdural Hematoma in the Aged (1963 1972)

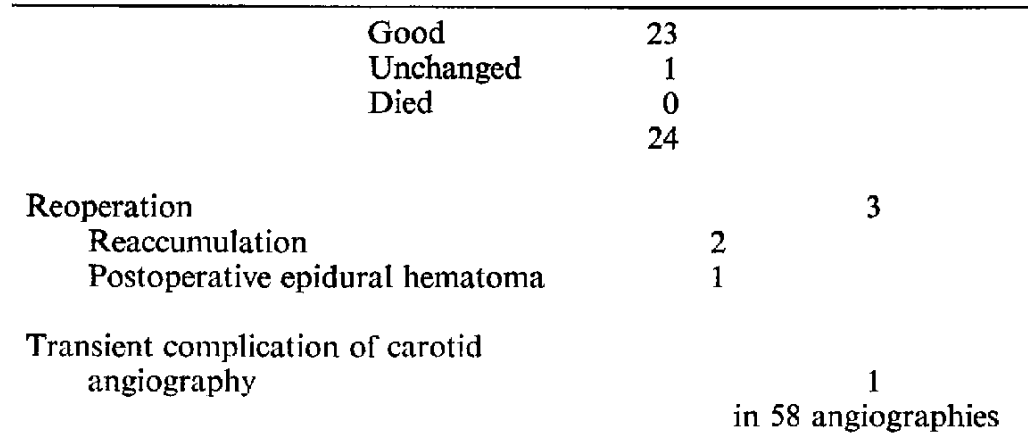

whose initial symptom had been loss of consciousness and admitted to a medical ward under the the diagnosis of vertebrobasilar thrombosis for 2 weeks, no improvement was obtained.

Carotid angiography was a safe procedure in the aged. In 24 patients, a total of 58 carotid angiographies was performed by a percutaneous direct carotid puncture. No untoward effect occurred except for one patient. In only one patient, 61-year-old male, postoperative right carotid angiography induced transient paresis of the left upper limb and dysphasia which disappeared in 3 hours. Later the contralateral carotid angiography showed good cross circulation but the right carotid had been occluded in the neck.

\section{Discussion}

With the increasing life expectancy of the general population, greater number of the older members is becoming subjects of neurosurgical care. In the patients of chronic subdural hematoma there is a steady increase to a maximum in the sixth or seventh decade before it declines (Table 8 ). In Svien and Gelety's series, ${ }^{16)} 53$ out of 69 (77 per cent) were more than 50 years old and 13 more than 70 years old. Allen, Moore and Daly ${ }^{2}$ found the peak incidence among inmates of mental hospitals to the seventh decade. 
Table 8 Age distribution of subjects with chronic subdural hematoma

\begin{tabular}{|c|c|c|c|}
\hline Age Authors & $\begin{array}{c}\text { Allen, Moore } \\
\text { \& Daily/ (1940) }\end{array}$ & $\begin{array}{l}\text { McKissock, Richardsoin } \\
\text { \& Bloom/ (1960) }\end{array}$ & $\begin{array}{l}\text { Weber } \\
(1969)\end{array}$ \\
\hline $0-9$ & $\mathrm{I}$ & 22 & 4 \\
\hline $10-19$ & 3 & 6 & 28 \\
\hline $20-29$ & 7 & 9 & 13 \\
\hline $30-39$ & 24 & 17 & 28 \\
\hline $40-49$ & 45 & 25 & 47 \\
\hline $50-59$ & 44 & 69 & 104 \\
\hline $60-69$ & 59 & 51 & 132 \\
\hline over 70 & 62 & 17 & 32 \\
\hline TOTAL & 245 & 216 & 388 \\
\hline
\end{tabular}

The clinical diagnosis of chronic subdural hematoma in the aged is often difficult.5111)12)13)15] Besides the sequalae of atherosclerotic brain damage, that is, presenile and senile dementia, generalized brain atrophy which is frequently accompanied with senility, contributes another impediment to the clinical recognition and/or suspicion of this disease. In the elderly patients in whom the brains have shrunken in size and whose subarachnoid space correspondingly widened, chronic subdural hematomas find sufficient room for their bulk in the first at the expense of extracerebral dilated subarachnoid space. It is to a lesser degree and later in the aged than in the younger patients that chronic subdural hematomas compress the brains. Localized neurological signs and symptoms, and signs and symptoms of increased intracranial pressure may often be less apparent at least in the initial stage. Symptom most frequently seen in the aged with chronic subdural hematoma is as a rule a generalized slowness of responsiveness.

A history of head injury may be absent or unobtainable. On occasions it is so trivial that it is forgotten readily. Closer interrogation, however, even after the surgical treatment discloses a high incidence of head injury. In our series, in spite of high incidence of a history of a probably causative injury ( 23 out of 24 ), a half of the patients had been first admitted to medical wards.

In this series initial symptom was gait disturbance in 67 per cent. And on admission to the Neurosurgical Ward one-third of the patients, that is, half of the alert patients, showed urinary incontinence. Differential diagnosis in the aged among chronic subdural hematoma, brain tumor, cerebral vascular disease $e^{\text {i),11) } 151}$ and normal pressure hydrocephalus is very difficult on clinical ground alone. Gait disturbance, urinary incontinence and dementia are the cardinal symptoms of normal pressure hydrocephalus. ${ }^{13}$ Echoencephalography, though it clearly shows the midline echo shift, does not always disclose a hematoma echo. Cerebral angiography is the method of choice.

In this series chronic subdural hematoma was neither associated with anticoagulant therapy nor hemodialysis. ${ }^{8)}$ The chronicity of epileptic convulsion ${ }^{3)}$ was not followed by the development of chronic subdural hematoma. Only one patient developed convulsion ${ }^{6)}$ on admission. No patient had whiplash injury. ${ }^{10},{ }^{17), 18)}$ No patients were associated with alcolism and with insanity. 
All the patients in this series had carotid angiography and had surgical treatment. No patient recovered without surgery. ( ) $^{2}$

There will always be a group of missed subdural hematoma. Recently, Kollvold7) reported 19 patients with slight head injuries admitted to the hospital, who were later re-admitted with subdural hematomas, and stressed that a strict control of the patients and instructions to the relatives about follow-up investigation are important.

\section{Summary}

A total of 106 patients of chronic subdural hematoma was found during 10 years from 1963 through 1972. Of these 24 (22.6 per cent) were older than 60 years old. Clinical analysis of these 24 patients was presented and the following results were obtained:

1. A history of head injury was taken in 23 patients ( 96 per cent).

2. Initial symptoms were gait disturbance in 67 per cent, psychiatric manifestations in 38 per cent, headache in 29 per cent and vomiting in 17 per cent.

3. A half of the patients had been first admitted to medical wards under the diagnosis of cerebral vascular lesion and others.

4. Neurological signs and symptoms on admission to the Neurosurgical Department were hemiparesis in 75 per cent, headache in only 38 per cent and choked disc in only 25 per cent. Psychiatric symptoms were found in one-sixth to one-fourth of the patients. Characteristically, urinary incontinence was found in 33 per cent of the total and in 50 per cent of the alert patients. Remission was observed in one-third of the patients.

5. Clinical diagnosis on admission to the Neurosurgical Department was following; chronic subdural hematoma in 63 per cent, brain tumor in 17 per cent and cerebral vascular lesion in 8 per cent.

6. Results of surgical treatment were excellent. There were no surgical mortality and no surgical morbidity. Carotid angiography was a safe and essential procedure even in the aged.

\section{References}

1) Adams, R. D., Fisher, C. M., Hakim, S., Ojemann, R. G. and Sweet, W. H.: Symptomatic occult hydrocephalus with "normal" pressure cerebrospinal fluid pressure. A treatable syndrome. New Eng. J. Med., 273:117, 1965.

2) Allen, A. M., Moore, M. and Daly B. B.: Subdural hemorrhage in patients with mental disease. New Eng. J. Med., 223:324, 1940.

3) Arieff, A. J. and Wetzel, N.: Subdural hematoma following epileptic convulsion. Neurology, 14:731, 1964.

4) Bender, M. B.: Recovery from subdural hematoma without surgery. J. Mount Sinai Hosp. N.Y., 27:52, 1960.

5) Bouzarth, W. F. and Bhatti, T. H.: Subdural hematomata in the elderly. J. Amer. Med. Wom. Ass., 23:631, 1968.

6) Cole, M. and Spatz, E.: Seizures in chronic subdural hematoma. New Eng. J. Med., 265:1961.

7) Kollevold, T.: Missed subdural hematomas. Present limits of neurosurgery. Proceedings 
of the fourth European Congress of Neurosurgery. Edited by Fusek I and Kunz Z, 1972, Excerpta Media, Avivenum, Czechoslovak Medical Press, Prague, 645-646.

8) Leonard, C. D.: Subdural hematoma and dialysis: Survey of reprint requests. New Eng. J. Med., 282:1433, 1970.

9) McKissock, W., Richardson, A. and Bloom, W. H.: Subdural haematoma: Review of 389 cases. Lancet $1: 1365,1960$.

10) Ommaya, A. K. and Yarnell, P.: Subdural haematoma after whiplash injury. Lancet $2: 237,1969$.

11) Perlmutter, I.: Subdural hematoma in older patients. JAMA 176:212, 1961.

12) Quandt, J.: Differentialdiagnose der Alternsprozesse des Gehirns und seiner Gefässe. Wien klin. Wschr. $81: 591,1969$.

13) Raskind, R., Glover, M. B. and Weiss, S. R.: Chronic subdural hematoma in the elderly: A challenge in diagnosis and treatment. J. Amer. Geriatr. Soc., 20:330, 1972.

14) Richter, H. H. und Teichmann, W.: Subdurale Hämatome unter besonderer Berücksichtung der katamnestischen Ergebnisse. Zbl. Chir., 94:492, 1969.

15) Rogers, L. A., Sternbergh, W. C., Jr., and Clark, K. : Subdural hematomas in the elderly. Southern Med. J., 65:930, 1972.

16) Svien, H. J. and Gelety, J. E.: On the surgical management of encapsulated subdural hematoma. J. Neurosurg. $21: 172,1964$.

17) Van Gijn, J. and Wintzen, A. R.: Whiplash injury and subdural hematoma. Lancet 2:592, 1969.

18) Waga, S., Ohtsubo, K., Ishikawa, M., and Handa, H.: Chronic subdural hematoma: Recent 10 years' experience. In preparation.

19) Weber, G.: Das chronische Subduralhämatom. Schweiz Med., Wschr. 99:1483, 1969. 